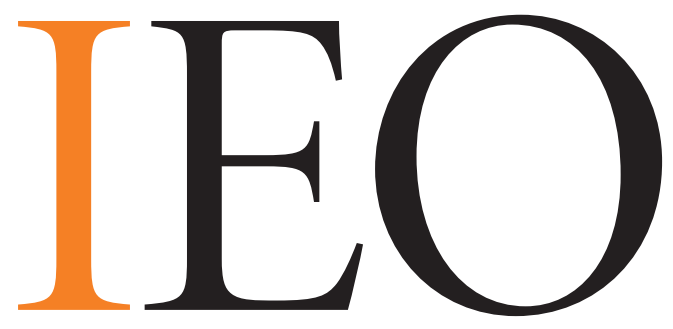

Independent Evaluation Office of the International Monetary Fund

\title{
Annual Report 2012
}




\section{Independent Evaluation Office}

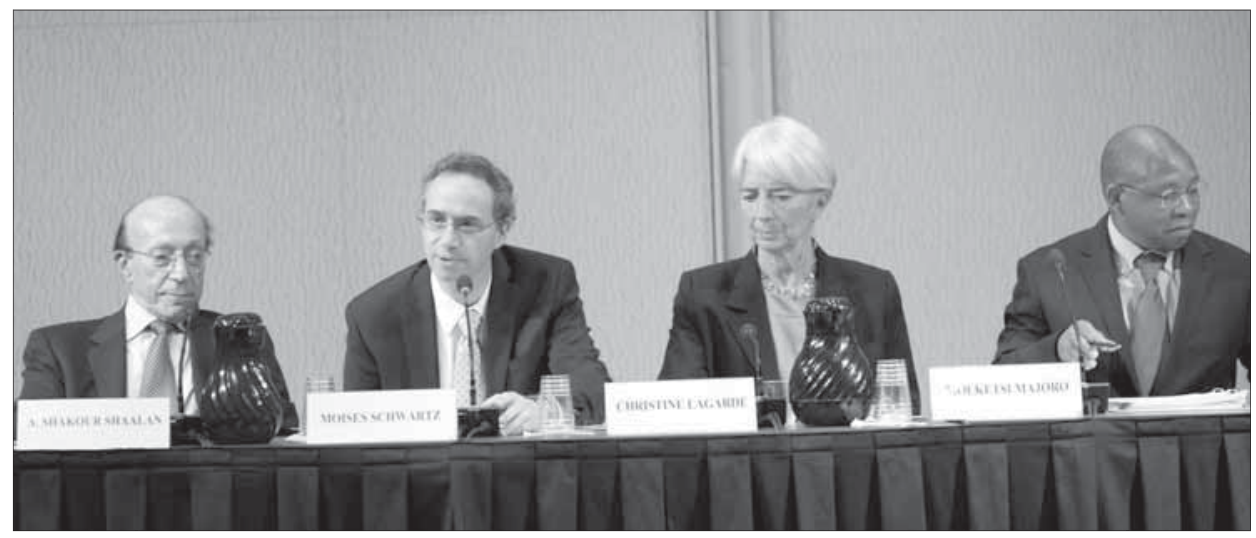

Opening session of the IEO conference on "Ten Years of Independent Evaluation at the IMF: What Does It Add Up To?" held in December 2011. Left to right: IMF Executive Director Shakour Shaalan, IEO Director Moises Schwartz, IMF Managing Director Christine Lagarde, and IMF Executive Director Moeketsi Majoro.

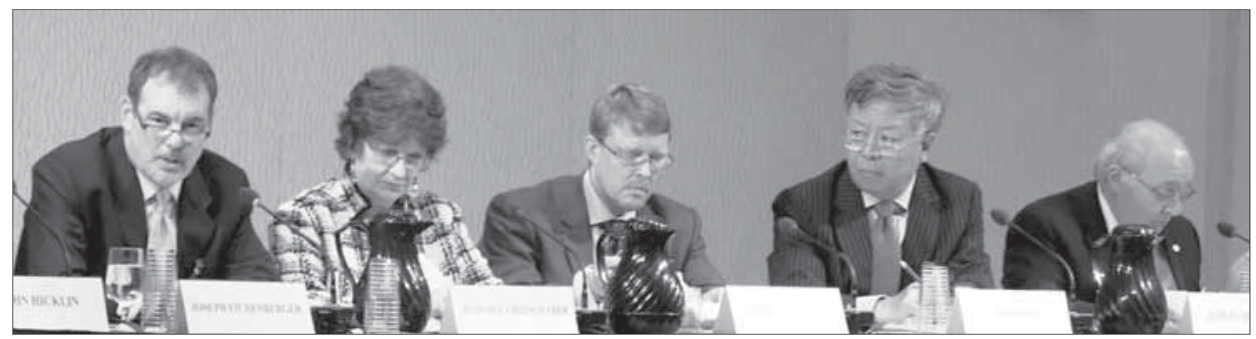

Panel of external stakeholders at IEO's December 2011 conference. Left to right: Joseph Eichenberger, Chief Evaluator, European Bank for Reconstruction and Development; Jo Marie Griesgraber, Executive Director, New Rules for Global Finance Coalition; Michael Hammer, Executive Director, One World Trust; Jin Liqun, Chairman of Supervisory Board, China Investment Corporation; and Edwin Truman, Senior Fellow, Peterson Institute for International Economics. stablished in July 2001, the
Independent Evaluation Office (IEO) provides objective and independent evaluation on issues related to the IMF. The IEO operates independently of IMF management and at arm's length from the IMF's Executive Board. Its goals are to enhance the learning culture within the IMF, strengthen the IMF's external credibility, promote greater understanding of the work of the IMF throughout the membership, and support the Executive Board's institutional governance and oversight responsibilities. For further information on the IEO and its work program, please see its website (www.ieo-imf.org) or contact the IEO at +1-202-6237312 or at ieo@imf.org.

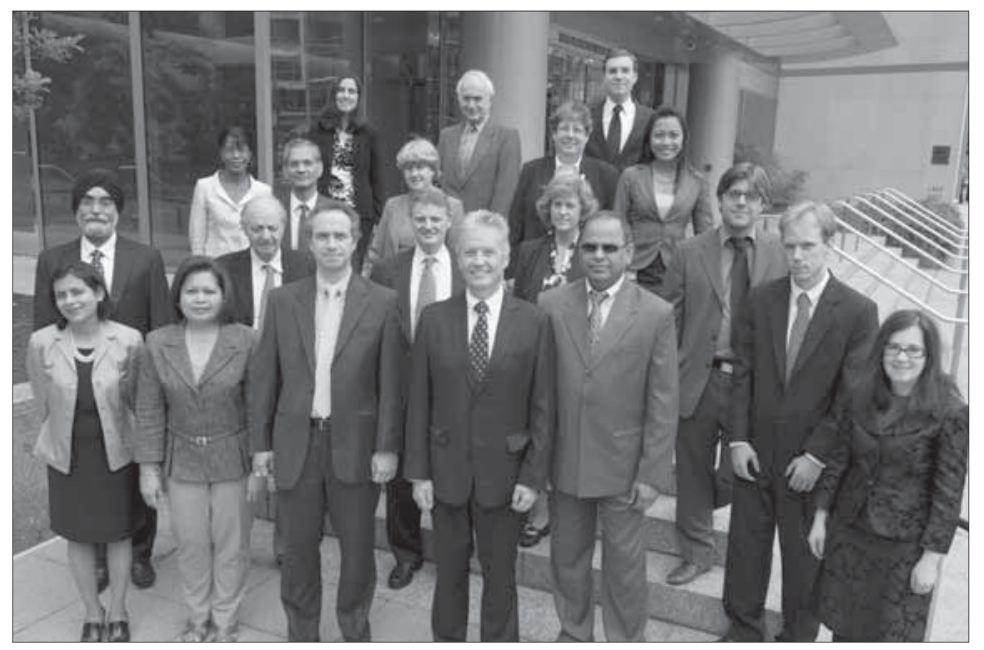

IEO staff and consultants.

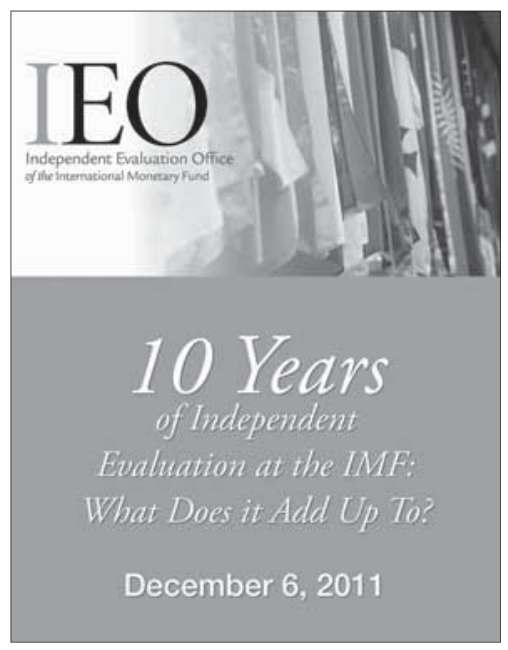

Conference poster. 


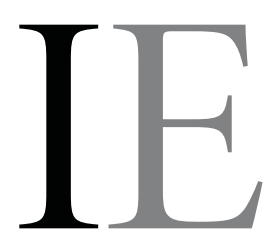

Independent Evaluation Office

of the International Monetary Fund

Annual Report

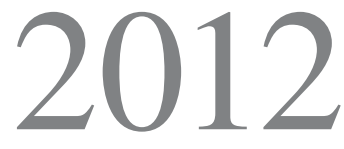


(C) 2012 International Monetary Fund

Cover: IMF Multimedia Services Division

ISBN 978-1-61635-411-4

Please send orders to:

International Monetary Fund, Publication Services

P.O. Box 92780, Washington, D.C. 20090, U.S.A.

Tel.: (202) 623-7430 Fax: (202) 623-7201

E-mail: publications@imf.org

Internet: www.imfbookstore.org 


\section{Contents}

Message from the Director $\underline{5}$

1 Overview of Developments in FY2012

Monitoring the Implementation of IEO Recommendations $\quad \underline{7}$

Budget and Staffing $\underline{8}$

Outreach and Communication Activities $\underline{8}$

2 Recently Completed Evaluations and Follow-Up on Past Evaluations

Research at the IMF: Relevance and Utilization

IMF Performance in the Run-Up to the Financial and

Economic Crisis: IMF Surveillance in 2004-07

3 Cross-Cutting Issues: The Framework for Follow-Up on IEO Evaluations

4 Ongoing Evaluations

Appendixes

1 Administrative Budget: Independent Evaluation Office

$\underline{17}$

2 Outreach Activities

$\underline{18}$

Table

1 Completed and Ongoing IEO Work Program

$\underline{16}$ 
This page intentionally left blank

(C) International Monetary Fund. Not for Redistribution 


\section{Message from the Director}

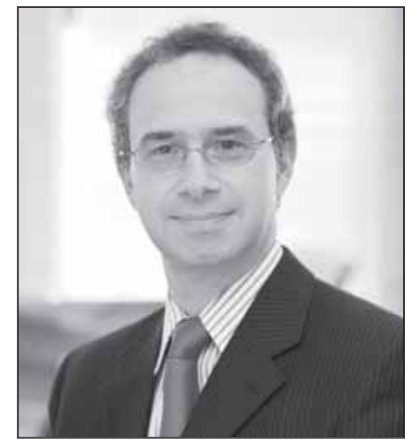

Tam pleased to present the ninth Annual Report of the Independent Evaluation Office (IEO), describing activities during the year from May 1, 2011, to April 30, 2012.

Last year marked the IEO's tenth anniversary. To reflect on its first decade, the IEO organized a conference on December 6, 2011 that brought together IMF Management, Executive Board members, senior staff, and external stakeholders, as well as current and past IEO teams. Participants discussed what the IEO has achieved so far and how the IEO can contribute further to the effectiveness and legitimacy of the IMF.

In opening the conference, I recollected that the IEO was created to strengthen learning and accountability at the IMF, and to enhance understanding among external stakeholders of how the institution works. These tasks are even more important today, when the legitimacy of, and trust in, the IMF are more critical than ever as it plays a central role in helping stabilize the world economy.

Since 2001, the IEO has produced 18 evaluation reports aimed at strengthening oversight, learning, and transparency — albeit with different emphases. A number of messages have recurred over time, including the need to: strengthen governance and clarify roles and responsibilities within the IMF; apply policies and frame advice with greater evenhandedness across the membership; provide incentives for staff to express alternative views internally and to raise difficult issues with country authorities; and better integrate analytical and operational work across departments, promoting more cooperation, fewer turf battles, and less silo-behavior.

The IEO itself has evolved over the decade. Following the external evaluation in 2006, the IEO has sought to place more emphasis on big policy issues; to target messages more carefully to the Executive Board and authorities; and to prepare more concise reports.

In reflecting on the office's work, conference participants expressed the strong sense that the IEO had demonstrated true independence, producing quality reports that have had an impact on the IMF. The Managing Director emphasized the importance of the IEO and looked forward to the IEO continuing to produce honest, fair, and demanding analysis. Several Executive Directors underscored that effective evaluation depends on engagement of all parties involved. They stated that the IEO's independence and internal access are crucial features that further both learning and oversight, and enhance the Fund's external credibility.

Conference participants also suggested lessons for the IEO and ways to enhance its work-including by evaluating IMF activities and performance with less of a lag, while still making sure that it does not interfere with IMF operations; and by making greater efforts to disseminate IEO work within and outside the IMF. Participants also reiterated weaknesses in the framework for implementation and monitoring of follow-up on Boardendorsed recommendations. (This issue is discussed further in Chapter 3 of this report.)

During FY2012, the IEO issued the report on its evaluation of Research at the IMF: Relevance and Utilization. The evaluation found that the IMF's vast body of research includes many high-quality products, many of which are widely read in member countries and play a significant role in policymaking - particularly the World Economic Outlook and the Global Financial Stability Report. At the same time, the evaluation found that there is significant scope to improve the relevance and quality of IMF research, and thus enhance its utilization. The report identified a number of steps to this end, including: early consultation with country authorities on research themes, better country and institutional contextualization, and clearer standards for quality control. 
Of particular importance, the Research evaluation found that many studies had conclusions and recommendations that did not appear to flow from the analysis, while other studies seemed to be designed with the conclusions in mind. Moreover, there was a widespread view among IMF staff that research findings need to be aligned with current IMF policies. The report called on IMF Management and the Executive Board to cultivate an open, independent, and innovative research environment, explicitly encouraging staff to explore differing and alternative views. It also recommended greater consultation and cooperation with country authorities, and an enhanced quality review process.

The findings and recommendations of this evaluation report, as well as the Executive Board's discussion, are described in Chapter 2. Chapter 2 also reports on the Management Implementation Plan for the IEO report on IMF Performance in the Run-Up to the Financial and Economic Crisis: IMF Surveillance in 2004-07. Also during FY2012, the IEO advanced its work on three new evaluations: "International Reserves: IMF Concerns and Country Perspectives;" "The Role of the IMF as Trusted Advisor;" and "An Assessment of Self-Evaluation Systems." These evaluations are described briefly in Chapter 4. We expect to issue these evaluation reports in FY2013.

The process of follow-up on IEO conclusions and recommendations, and monitoring thereof, remain areas of concern for the IEO and the Executive Board of the IMF. During the past year, this was reflected in the back and forth discussions on Management Implementation Plans and the Periodic Monitoring Report, described in some detail in this Annual Report. On May 22, 2012, after the start of FY2013, the IMF Executive Board approved terms of reference for the second external evaluation of the IEO and identified the adequacy of the evaluation process, including follow-up, as an area to be assessed. The IEO looks forward to the conclusions of the external evaluation on this and other issues, which should serve to strengthen the process of independent evaluation at the IMF.

As we begin a second decade of independent evaluation at the IMF, the IEO remains committed to helping enhance IMF effectiveness in these challenging times.

\author{
Moises J. Schwartz \\ Director \\ Independent Evaluation Office
}




\section{Overview of Developments in FY2012}

D uring financial year 2012, the IMF Executive Board discussed the IEO evaluation of Research at the IMF: Relevance and Utilization. Directors also considered the Fourth Periodic Monitoring Report (PMR) on the Status of Implementation Plans in Response to Board-Endorsed IEO Recommendations. In December 2011, the IEO hosted a conference to mark the conclusion of its first decade of operations. Work also continued on three evaluations: "International Reserves: IMF Concerns and Country Perspectives;" "The Role of the IMF as Trusted Advisor;" and "An Assessment of SelfEvaluation Systems."

This chapter summarizes overall developments in the financial year. Chapter 2 summarizes the findings and recommendations of the Research evaluation and the Board discussion of this evaluation-as well as the Board discussion in very early FY2013 of the Management Implementation Plan (MIP) for the IEO evaluation of The IMF's Performance in the Run-Up to the Financial and Economic Crisis: IMF Surveillance in 2004-07. Chapter 3 discusses cross-cutting issues related to IEO work. Chapter 4 addresses ongoing evaluations.

\section{Monitoring the Implementation of IEO Recommendations}

As of end-FY2012, the MIPs for the two most recent IEO evaluations had not yet been agreed by the Board. IMF staff provided a revised MIP for the Financial and Economic Crisis evaluation on December 22, 2011. ${ }^{1}$ The Evaluation Committee discussed the revised MIP on January 24, 2012; the full Board discussed and agreed to the MIP on May 25, 2012-after the end of FY2012. (See discussion in Chapter 2.) On June 18, 2012,

\footnotetext{
${ }^{1}$ The Evaluation Committee discussed an initial MIP in April 2011 but agreed to postpone formal consideration of the implementation plan for this evaluation until after completion of the 2011 Triennial Surveillance Review. See Chapter 2 for further details.
}

IMF staff circulated to the Evaluation Committee a MIP on the Research evaluation. ${ }^{2}$ The MIP will be reviewed by the Evaluation Committee at a date to be determined and will subsequently be considered by the full Board.

The Fourth PMR, which was presented by staff near the end of the previous financial year in March 2011, was discussed by the Evaluation Committee on July 26, 2011. This PMR concluded that key performance benchmarks related to the IEO evaluation of IMF Involvement in International Trade Policy Issues had been met, or were on track for timely completion. It also concluded that there were no outstanding benchmarks to be reviewed in the next PMR, although it stated that the next PMR will provide further updates as necessary on broader issues raised in the context of the Fourth PMR. The Fourth PMR also provided a brief update on several issues that the Evaluation Committee identified as needing further reflection and future work when it discussed the previous PMR, including the status of upgrades to the database to monitor IMF-supported arrangements (MONA), and measures to ensure longer country assignments. However, the Fourth PMR did not address two additional issues that the Evaluation Committee had also highlighted: the treatment of confidential information in Article IV staff reports; and the process for monitoring implementation of IEO recommendations in the Governance evaluation.

The Evaluation Committee broadly endorsed the Fourth PMR's assessment that key performance benchmarks related to the MIP for the Trade evaluation had been met or were on track for timely completion and that there were no outstanding benchmarks to be reviewed in the next PMR. However, looking beyond implementation of the Trade MIP, the Committee considered that further work was needed to address staff mobility, an issue raised more than once in IEO evaluations.

\footnotetext{
${ }^{2}$ The Research evaluation was issued by IEO in May 2011 and discussed by the Board in June 2011.
} 
The Committee also called for expansion of monitoring in subsequent PMRs to highlight the status of past implementation plans, and thereby to facilitate an overall assessment by the Board of how effectively IEO recommendations were being implemented. In addition, the Committee agreed on the need to strengthen the process for endorsing IEO recommendations, as well as related follow-up. Nonetheless, the Evaluation Committee recommended Board approval of the Fourth PMR on a lapse-of-time basis; this approval took place on August 26, 2011.

\section{Budget and Staffing}

In FY2012, the IEO expended approximately 97 percent of its total budgetary resources, including the approved budget amount and the resources carried forward from FY2011 as authorized. Appendix 1 details the IEO budget and expenditures. In sum, vacancies amounted to about one and one-half staff years over the course of the financial year. This level of vacancies is within the range of what could be expected in a small organization with structural difficulties in recruitment and retention, as discussed in past Annual Reports. Spending on staff was thus less than budgeted, while spending on contractual services and travel was higher than the budgeted level. In addition, the timing of several publications slipped beyond FY2012, resulting in a shortfall in expenditure on publications that will likely be offset by increased spending in this area in FY2013.

On April 10, 2012, the IMF's Executive Board approved the IEO budget proposal for FY2013 of $\$ 5.5$ million, consistent with zero real growth over FY2012. This proposed budget, along with unspent funds carried over from the FY2012 budget, ${ }^{3}$ will allow the IEO to implement its planned work program for FY2013namely to complete three ongoing evaluations as indicated above and to launch two new evaluations. The IEO also presented indicative budgets for FY2014 and FY2015, based on zero real growth.

\section{Outreach and Communication Activities}

The IEO continued to follow through on the recommendations of the 2006 External Evaluation report to engage in outreach as a "necessary tool" to inform stakeholders about IEO analyses and findings in order to increase their impact. The IEO recently revamped its website. The new design is more user-friendly, facilitating access to completed evaluations, issues papers for ongoing evaluations, the IEO work program, and other IEO publications. The IEO also publishes a semiannual newsletter, available in English, French, Portuguese, Russian, and Spanish.

To publicize and encourage discussion of its work, the IEO organized or participated in a number of events in FY2012, listed in Appendix 2. Of note, the IEO organized a conference in December 2011 to reflect on its first decade of operations. At the conference, Executive Directors, IMF Management, senior staff, and external stakeholders came together to discuss what the IEO has achieved and how it can further contribute to the effectiveness of the IMF. The conference agenda, opening remarks by IEO Director Moises Schwartz, and videos of each session are available on the IEO website (see www.ieo-imf.org).

\footnotetext{
${ }^{3}$ The IEO is authorized to carry forward unspent funds up to a limit of 5 percent of the previous year's budget.
} 


\section{Recently Completed Evaluations and Follow-Up on Past Evaluations}

D uring FY2012, the IEO issued the report on its evaluation of Research at the IMF: Relevance and Utilization, which was discussed by the Executive Board on June 13, 2011.

\section{Research at the IMF: Relevance and Utilization}

This evaluation examined the research produced at the IMF between 1999 and 2008, focusing on the relevance and utilization of the research, particularly as seen by authorities in member countries. It also examined the technical quality and the management of research activities. Research was defined broadly to capture most analytical publications of the IMF, ranging from surveillance-oriented output to more academically-oriented output - together comprising a body of research of about 650 publications annually, at a cost of about 10 percent of the IMF budget.

\section{Findings and conclusions}

The evaluation found that the IMF produced a vast body of research that was widely read, included a large number of high-quality and very useful publications, and was appreciated by country authorities and the research community. This was particularly true for the World Economic Outlook (WEO) and Global Financial Stability Report (GFSR), but also for many other publications. Given the attention they received from member country authorities, IMF research publications played a significant role in policymaking and were relied upon by authorities in their discussions with IMF staff. IMF research was also influential among other international organizations, academics, and think tanks.

At the same time, the evaluation found that there was significant scope to improve the relevance and quality of IMF research, and hence enhance utilization.
First, the relevance of research was often hampered by the lack of early consultation with country authorities on research themes and by a lack of sufficient country and institutional context. Also, authorities indicated that some important issues, such as macrofinancial linkages and aspects of monetary policy, were not adequately covered. A majority of country authorities reported that they were not consulted on the choice of topics for Selected Issues Papers (SIPs), which also used analytical frameworks poorly suited to their countries' situation and did not reflect a good knowledge of local institutions. In regions other than Africa, authorities indicated that generic regional analysis and an absence of in-depth comparative or cross-country research limited the usefulness of Regional Economic Outlooks (REOs). And many country authorities were also disappointed by the small amount of collaboration on research projects between local researchers and the IMF.

Second, the technical quality of IMF research publications was quite diverse. The WEO, GFSR, and external publications were generally of high and consistent technical quality. On the other hand, the quality of SIPs and Working Papers (WPs), which were not subject to a rigorous quality review, was lower and more variable. Some WPs made a contribution to the literature and were extensively cited, and most other WPs and SIPs were of adequate quality. The quality of other WPs and SIPs, as well as some analytical chapters of the REOs, however, was below satisfactory. This was found to be a serious concern, as most country authorities perceived these publications as having been closely reviewed, if not endorsed, by the IMF and accordingly took their findings and recommendations into account in policy analysis. Low-quality publications also negatively affected the reputation of all research. The evaluation found that short time frames and limited resources contributed to the low quality of some publications, particularly SIPs, as did the absence of IMF-wide quality standards or a uniform review process. 
Third, there was a widely held perception that IMF research was message-driven. About half of the authorities held this view, and more than half of the staff indicated that they felt pressure to align their conclusions with IMF policies and positions. Policy recommendations provided in some research publications did not follow from research results. Further, a number of country authorities and researchers noted that IMF research tended to follow a pre-set view with predictable conclusions that did not allow for alternative perspectives-detracting from the quality and credibility of studies and reducing their utilization.

In addition, the evaluation found that it was difficult for country authorities and IMF staff alike to distill relevant findings and policy implications from IMF research, given its large volume and the lack of a simple way to search through the IMF's research outputs. And finally, the evaluation found IMF-wide leadership of research lacking. Research activities were highly decentralized, with very limited coordination across departments and no mechanism to set IMF-wide priorities or quality standards. Collaboration among staff across departments was limited and mostly based on personal relationships. Many agreed that there was scope to better prioritize research activities across the IMF and to improve quality assurance.

\section{IEO recommendations}

The evaluation presented four main categories of recommendations aimed at addressing the shortcomings identified.

To enhance the relevance of research, the IMF should:

- Conduct a periodic strategic review of the function and uses of its research product lines to establish whether they should be strengthened, redesigned, or discontinued. An indicative medium-term research agenda should be prepared in consultation with member countries and the Executive Board. This agenda should be made publicly available. It should not be seen as excluding research on other themes and areas.

- Make it standard practice to consult with authorities on research topics and to discuss preliminary results with authorities and other in-country experts, in order to enhance the country and institutional context of research, particularly SIPs.
Longer country assignments by mission members would also enable greater familiarity with country conditions, as would collaboration with authorities on research projects.

To enhance the technical quality of analytical work, the IMF should:

- Allocate adequate time and resources to each research project, even if this leads to fewer publications.

- Establish clear standards for technical quality of different research products. Strengthened quality assurance and review processes should be introduced to this end. For example, WPs could be subjected to a well-structured external peer review, to help promote greater openness to new and alternative ideas, as well as to weed out low-quality products.

- Strengthen incentives to improve the quality of research. For example, Management should clarify that staff annual performance evaluations will assess the quality of research as well as the quantity.

To promote openness to alternative perspectives, the IMF should:

- Allow researchers to explore issues without preconceived conclusions or messages. The Board, Management, and senior staff should actively foster an environment that encourages innovative research and should establish incentives for staff to pursue such research. After a thorough quality review, staff should be able to publish WPs and other academic-style products even when the results of their analysis are not well aligned with messages in surveillance documents.

To improve the management of IMF research, IMF Management should:

- Designate a senior staff member to be the leader and advocate of research activities across the IMF. This leader would be responsible for coordinating research activities across the IMF, including by setting standards for quality review processes and publication policies and promoting openness to alternative perspectives. The coordinator should report annually to member countries and the Board on research priorities and achievements. 


\section{Management and staff response}

IMF Management found the IEO evaluation to reflect a balanced assessment of Fund research and welcomed its constructive recommendations. The Acting Managing Director also noted progress made by staff since the conclusion of the review period in tackling relevant policy issues in their research work.

IMF staff welcomed the overall findings and agreed that a number of key issues required further consideration, including suggestions for periodic strategic reviews of research, better allocation of resources to research projects, enhanced review processes, and vigilance against the risk of message-driven research. They noted that it is particularly important that IMF researchers not feel that they need to toe a line or tilt empirical results. At the same time, they expressed concern that a medium-term research agenda may limit flexibility and could be quite bureaucratic, that consultation on research topics with authorities should vary by product, and that coordination of research could stifle individual research efforts.

\section{Executive Board discussion}

The IMF Executive Board discussed the evaluation on June 13, 2011. Following are key excerpts from the Summing Up of the Board discussion.

Executive Directors welcomed the IEO report, noting that it provides a balanced assessment of the quality, relevance, management, and utilization of IMF research....

Noting that IMF research is of uneven quality and perceived to be message-driven, however, Directors saw scope for enhancing the relevance and technical quality of the analytical work, openness to alternative points of view, and coordination of research activities across the institution. Directors looked forward to considering concrete steps to take forward the IEO recommendations, complementing efforts underway.

Directors broadly shared the main IEO findings. They concurred that, while global and core macroeconomic issues were adequately covered in IMF research, up until 2008, there were some gaps in the coverage of macro-financial linkages and capital account issues. They acknowledged, however, that efforts since then have narrowed these gaps, and urged staff to build on this progress. Directors also noted gaps in country-level research, especially for low-income countries where the influence of IMF research on policymaking is greatest....

Directors considered worrisome the finding that there is a widely held perception that IMF research is message- driven, or that policy conclusions do not always follow from the analysis. While recognizing that research produced by the IMF will inevitably carry policy messages-especially surveillance-oriented researchthey considered it critical for the credibility of the institution that the conclusions of in-house research are not biased by the IMF's position on the subject or excessively influenced by other work done internally, and, conversely, that its policy advice is grounded on robust analysis. In this context, many Directors underlined the importance of addressing concerns about the internal culture and institutional values-identified in previous IEO evaluations - with a number of Directors regarding staff diversity in terms of academic background and professional experience as critical in this regard. More broadly, Directors stressed that IMF research should aim primarily at improving the analytical tools for the IMF to carry out its core mission.

Directors agreed on the need for improved dissemination of IMF analytical work, allowing a wider group of stakeholders to distill relevant lessons and increasing its contribution to the policy debate....

Directors broadly endorsed the main recommendations of the IEO, and looked forward to further analysis and discussion in the context of the forthcoming Management Implementation Plan.

Directors generally saw merit in conducting a periodic strategic review of research products. Management and staff were encouraged to focus on how best to allocate resources among the various research product lines... and to strengthen quality controls, the internal review process, and incentives to enhance the technical content of research, while taking into account budget constraints. More specifically, some Directors suggested re-examining the value-added of Regional Economic Outlook reports, while a few highlighted their usefulness to intended audiences. Most Directors also supported the IEO recommendation to set an indicative medium-term research agenda, possibly in consultation with member countries and the Executive Board, although a few Directors were not in favor of Board involvement in the agenda-setting process. At the same time, Directors underscored the need to retain adequate flexibility for staff to take on independent research projects.

Directors broadly supported the IEO recommendation to consult more with country authorities on research topics prepared for bilateral and regional surveillance, particularly for Selected Issues Papers. Recognizing that staff and the authorities do not always agree on the prioritization of issues, Directors agreed that staff should remain free to research the issues that they feel are most important. Longer country assignments for mission members could facilitate collaboration with authorities and enhance familiarity with country-specific conditions. 
Directors agreed on the need to improve the management of IMF research and were open to the various proposals to achieve that objective....

\section{Management Implementation Plan and follow-up}

On June 18, 2012, IMF staff circulated to the Evaluation Committee a MIP on the IEO evaluation of Research at the IMF: Relevance and Utilization-a year after this report was discussed by the Executive Board. The MIP will be reviewed by the Evaluation Committee at a date to be determined, and will subsequently be considered by the full Board.

\section{IMF Performance in the Run-Up to the Financial and Economic Crisis: IMF Surveillance in 2004-07}

An initial MIP for this evaluation was prepared in March 2011. Following an initial discussion of this proposed MIP in April 2011, the Evaluation Committee decided to postpone formal consideration of an implementation plan until after completion of the Triennial Surveillance Review (TSR) then under preparation. IMF staff subsequently outlined plans for moving ahead in other areas (e.g., diversity, Summing Up process) that were not under discussion in the TSR.

A revised implementation plan was prepared by staff in December 2011, following the issuance of the TSR. This revised MIP was discussed by the Evaluation Committee in January 2012. At this meeting, Directors emphasized the need for further steps to address the conclusions of the IEO evaluation and also expressed a desire for more information about Management's strategic vision on internal reforms. The Committee also decided that the MIP should be considered at a meeting of the full Executive Board. The MIP was issued to the full Board for its consideration on February 14, 2012.

On May 25, 2012, after the close of FY2012, the Board discussed the revised MIP, together with a statement by the Managing Director describing some recent initiatives undertaken to address cultural and structural weaknesses identified in the IEO evaluation. Directors generally considered that the Managing Director's statement and the proposed implementation plan complemented well the action plan for the TSR, and together should help enhance the effectiveness of Fund surveillance.

Directors emphasized that a comprehensive longterm approach is needed to tackle the shortcomings highlighted in the IEO report. They broadly supported the specific proposals in the implementation plan, and welcomed Management's statement on an ambitious agenda to break down silos and promote diverse views and candor, further advancing initiatives under way. Directors considered that the MIP, together with Management's proposed agenda, provided a good start and encouraged Management and staff to continue to build on them, and where appropriate, engage the Board in the process.

Directors focused their discussion in particular on actions to: encourage candor and diverse views; speak up to power; integrate financial sector issues into macroeconomic assessments; break down silos; and deliver a clear and consistent message on the economic outlook and risks. Key action items included establishment of a Board Working Group on Summings Up Review, which was expected to provide its recommendations to Management before the 2012 summer recess.

Directors stressed the importance of monitoring and verifying progress on all these fronts in the context of future PMRs. They noted that changing the institutional culture is a continuous, long-term process and looked forward to revisiting this issue in one year. The Managing Director also recognized that some Directors believed that the incremental steps already under way and proposed may still not fully address remaining concerns or more fundamental problems-including governance reforms. She pledged to monitor progress and adapt over time.

A Public Information Notice with the full Summing Up of the Board discussion was posted on the IMF website on June 6, 2012. 


\section{Cross-Cutting Issues: The Framework for Follow-Up on IEO Evaluations}

$T_{\text {th }}^{\text {hech }}$ he effectiveness and soundness of the institutional framework for follow-up on IEO evaluations continued to be an area of concern during FY2012. The issue was discussed by the Board, the Evaluation Committee, Management, and staff, in addition to being the focus of much attention during the conference that took place on December 6, 2011, to mark the IEO's first decade of operations. Concerns have been expressed both about the extent of implementation of IEO conclusions and recommendations endorsed by the Board, as well as the quality and consistency of monitoring of this implementation. Key questions include:

- Do Summings Up of Board discussions accurately reflect the views expressed during the Board discussion of IEO evaluations?

- Are MIPs well aligned with Summings Up and with Board views? Do they take into account the broad conclusions and recommendations endorsed by the Board, in addition to specific actions?

- Are there sufficient systems in place for Management and staff to monitor the implementation of these conclusions and recommendations?

- Does the PMR enable the Board and other stakeholders to understand the extent of implementation?

The current framework for following up on IEO evaluations was put in place in January 2007. This followed the 2006 Report of the External Evaluation of the IEO, which identified a "clear need for more systematic monitoring of follow-up" and called on the Executive Board to take a lead role in this regard. The Board subsequently adopted a framework with two key components: (1) a forward-looking implementation plan for Board-endorsed IEO recommendations (MIP), to be provided by Management to the Board soon after discussion of the evaluation; (2) a periodic monitoring report (PMR), to be presented to the Board about once each year, on the status of implementation of actions agreed to implement Board-endorsed IEO recommendations. These reports were also intended to indicate difficulties in implementing the original plan and propose remedial or substitute actions whenever appropriate.

As noted in past Annual Reports, the Evaluation Committee and other Executive Directors have raised concerns about the follow-up process since this framework was put in place. In its discussion of the first PMR in January 2008, the Executive Board considered that monitoring would benefit from greater specificity and clarity of the follow-up actions required-including in their articulation in Board discussions and Summings Up, as well as in MIPs. In reviewing the Third PMR, Directors noted that, on some occasions, concerns raised by IEO that were broadly shared by the Board had not been addressed in implementation plans, since a specific recommendation had not been explicitly endorsed. Some Directors have also noted that more needs to be done in some cases to achieve the broader policy objectives underlying specific IEO recommendations, despite the fact that agreed implementation actions may have been completed. In discussing the Fourth PMR (as noted in Chapter 1), the Evaluation Committee requested that the subsequent PMR provide updates as necessary on broader issues raised by previous evaluations.

The need to strengthen the follow-up process also received some attention from IMF staff in FY2012. In the revised MIP for the Financial and Economic Crisis evaluation, IMF staff agreed, as a first step, to include a comprehensive analysis of all Board-endorsed IEO recommendations in future PMRs. In discussing the MIP, Directors raised a number of concerns about the process for monitoring different strands of work to follow up on this evaluation. In addition, there was also a call for Management to develop concrete and measurable norms to monitor and improve the follow-up of the IEO's recommendations more broadly.

In an effort to help shed light on the extent of implementation of its recommendations as well as on how implementation is being monitored, the IEO undertook 
a study this year focused on seven evaluations completed in 2005-09. ${ }^{4}$ The study reviewed the implementation of high-level recommendations that were endorsed, at least in part, by the Board. ${ }^{5}$ The study concluded that most IEO recommendations had been implemented, to different degrees, but that issues remained with respect to many of these recommendations. Across the seven evaluations in the review sample, implementation appeared to have proceeded consistent with the Board position for about one-quarter of the high-level, Board-endorsed recommendations. For an additional 50 percent, some action had been taken, but there were issues with implementation; for instance, some actions were taken but efforts stalled before the desired results were achieved. For about 15 percent, minimal or no direct follow-up action was found. ${ }^{6}$ And for about 10 percent, insufficient information was found to assess the status.

The large share of Board-endorsed recommendations with issues still outstanding raises questions about the follow-up process, particularly given that the study examined only those recommendations that had been endorsed by the Board and addressed by MIPs. It also raises questions about the current monitoring system,

\footnotetext{
${ }^{4}$ This study will be published as part of the forthcoming IEO book "Independent Evaluation at the IMF: The First Decade."

${ }^{5}$ The IEO made 117 high-level and about 160 less critical recommendations in the 18 evaluations it issued during 2002-11. About 85 percent of the high-level recommendations were endorsed to some degree by the Board. In the 7 evaluations in the sample, there were 41 high-level recommendations of which 38 were endorsed by, or received partial or nuanced support from, the Executive Board (a higher proportion than in other IEO evaluations).

${ }^{6}$ In some instances, IMF staff had linked particular action to certain recommendations, but the IEO concluded that these did not address the relevant concerns.
}

since recent PMRs have concluded that all key performance benchmarks specified in earlier MIPs had either been met or were on track for timely completion and that there is no need to review current and past performance benchmarks in the following PMRs.?

The IEO study of implementation also analyzes the issues behind the delayed and/or halting implementation of a few recommendations. Some recommendations called for action on challenging issues, for which IMF staff may need time to reflect to identify solutions; other recommendations may encounter resistance from within or outside the IMF. The examples in the study are illustrative and not necessarily representative, but they may help identify weak aspects of the follow-up framework, and may assist in contemplating necessary changes.

Going forward, the IEO is considering revisiting the implementation of past recommendations in a more systematic way. The modalities for this exercise are not yet clear, but the IEO is exploring the idea of revisiting one or two of its early evaluations as a pilot project in the context of the FY2013 Annual Report. Such an exercise could examine the continued relevance of lessons from the corresponding evaluation in the current context, whether recommendations remain useful, and the extent to which they have been implemented.

\footnotetext{
${ }^{7}$ Third and Fourth Periodic Monitoring Report on the Status of Implementation Plans in Response to Board-Endorsed IEO Recommendations, October 9, 2009 and March 14, 2011, respectively. The Fourth PMR indicated that "the next PMR will provide further updates as necessary on broader issues raised in the context of this report."
} 


\section{Ongoing Evaluations}

A $t$ the end of FY2012 the IEO was working on three evaluations that it expects to complete during FY2013:

- The evaluation of "International Reserves: IMF Concerns and Country Perspectives" examines the conceptual basis of concerns at the IMF about the effects of reserve accumulation on the stability of the international monetary system, and assesses the nature and quality of the IMF's advice on reserve adequacy in the context of bilateral surveillance.

- The evaluation of "The Role of the IMF as Trusted Advisor" examines authorities' confidence in the quality and relevance of IMF advice, together with other factors that might influence the persuasiveness of advice and the desire to engage the Fund in a policy dialogue. It looks at the period from 2005 through the present-including the aftermath of the global financial and economic crisis. The evaluation considers, in particular, whether the IMF's role as a trusted advisor has changed relative to the past.
- "An Assessment of Self-Evaluation Systems." This evaluation will examine whether there are processes in place for IMF Management and staff to draw lessons from experience by determining what works and how; and whether and how lessons are shared within and across units. This evaluation is the first assessment of self-evaluation systems undertaken within the IMF, and it will focus mainly on taking stock of such activities, leaving an assessment of quality and impact for future evaluations.

Finally, the IEO is producing a volume describing the IMF's experience with independent evaluation over the past 10 years. In addition to the proceedings of the December 6, 2011 conference, the volume will include several self-evaluative papers discussing the IEO's history, the nature and utilization of IEO reports, and the implementation of Board-endorsed IEO recommendations. The analysis prepared for this volume is part of the IEO's own learning process and is aimed at enhancing IEO's contributions to the IMF and its membership.

Table 1 shows the status of IEO evaluations completed or in progress. 
Table 1. Completed and Ongoing IEO Work Program

\begin{tabular}{|c|c|}
\hline Project & Status \\
\hline Prolonged Use of IMF Resources & Completed (August 2002) \\
\hline The IMF and Recent Capital Account Crises & Completed (May 2003) \\
\hline Fiscal Adjustment in IMF-Supported Programs & Completed (July 2003) \\
\hline The IMF and Argentina, |99|-200I & Completed (July 2004) \\
\hline The IMF's Role in PRSPs and the PRGF & Completed (June 2004) \\
\hline IMF Technical Assistance & Completed (January 2005) \\
\hline The IMF's Approach to Capital Account Liberalization & Completed (April 2005) \\
\hline IMF Support to Jordan, 1989-2004 & Completed (October 2005) \\
\hline Financial Sector Assessment Program & Completed (November 2005) \\
\hline Multilateral Surveillance & Completed (March 2006) \\
\hline Structural Conditionality in IMF-Supported Programs & Completed (October 2007) \\
\hline The IMF and Aid to Sub-Saharan Africa & Completed (January 2007) \\
\hline IMF Exchange Rate Policy Advice & Completed (March 2007) \\
\hline Governance of the IMF & Completed (April 2008) \\
\hline IMF Involvement in International Trade Policy Issues & Completed (May 2009) \\
\hline IMF Interactions with Member Countries & Completed (November 2009) \\
\hline $\begin{array}{l}\text { IMF Performance in the Run-Up to the Current Financial and } \\
\text { Economic Crisis: IMF Surveillance in 2004-07 }\end{array}$ & Completed (January 20II) \\
\hline Research at the IMF: Relevance and Utilization & Completed (May 20II) \\
\hline International Reserves: IMF Concerns and Country Perspectives & In progress \\
\hline The Role of the IMF as Trusted Advisor & In progress \\
\hline An Assessment of Self-Evaluation Systems & In progress \\
\hline
\end{tabular}




\section{Appendix 1}

Administrative Budget: Independent Evaluation Office

(In U.S. dollars)

\begin{tabular}{|c|c|c|c|c|c|}
\hline & \multicolumn{2}{|c|}{ FY20II } & \multicolumn{2}{|c|}{ FY20I2 } & \multirow{2}{*}{$\begin{array}{c}\text { FY20I3' } \\
\text { Approved } \\
\text { Budget }^{2,5}\end{array}$} \\
\hline & $\begin{array}{l}\text { Approved } \\
\text { Budget }^{2}\end{array}$ & Outturn $^{3}$ & $\begin{array}{l}\text { Approved } \\
\text { Budget }^{2}\end{array}$ & Outturn $n^{3,4}$ & \\
\hline Total & $5,432,785$ & $5,350,186$ & $5,508,844$ & $5,610,094$ & $5,542,44$ \\
\hline Regular staff allocation & $3,795,730$ & $3,356,718$ & $4,281,320$ & $3,86 I, 427$ & $4,258,930$ \\
\hline $\begin{array}{l}\text { Discretionary budget } \\
\text { Of which: }\end{array}$ & $\mathrm{I}, 637,055$ & $1,993,468$ & $\mathrm{I}, 227,524$ & $\mathrm{I}, 748,667$ & $1,283,5 \mid 8$ \\
\hline Contractual services (including overtime) & 883,104 & $1,226,194$ & 602,268 & $1,102,719$ & 602,268 \\
\hline Business travel and seminar program & 537,011 & 599,322 & 402,917 & 468,458 & $4 I I, 057$ \\
\hline Publications & 148,820 & 75,101 & 105,987 & 15,558 & 16,310 \\
\hline Other fungible budgets & 68,120 & 92,851 & 116,352 & 161,932 & 253,883 \\
\hline
\end{tabular}

'The figures for FY2013 were estimated by Office of Budget and Planning.

${ }^{2}$ Starting in FY20I0, the IEO is authorized to carry forward unspent funds up to a limit of 5 percent of the previous year's budget.

${ }^{3}$ IEO estimates.

${ }^{4}$ Total resources available to the IEO for FY20I2 equaled $\$ 5,780,344$, which included a carry forward of $\$ 271,500$ from FY20II, in addition to the approved budget. At $\$ 5,610,094$, IEO expenditures in FY20 I 2 represented approximately 97 percent of its total resources.

${ }^{5}$ Total resources available to the IEO for FY20I3 will include an estimated carry forward of about $\$ 200,000$ from FY20I2, in addition to the approved budget of $\$ 5,542,448$. 


\section{Appendix 2 Outreach Activities}

May 2010, Cartagena, Colombia

IEO Director's presentation on the evaluation of $I M F$ Performance in the Run-Up to the Financial and Economic Crisis: IMF Surveillance in 2004-07 at the 91st meeting of central bank governors at the regional association of Latin American and Caribbean central banks (CEMLA).

\section{June 2011, Berlin, Germany}

Joint seminar with the German Federal Ministry for Economic Cooperation and Development (BMZ) to discuss the evaluation of IMF Research: Relevance and Utilization and to consider issues for the new evaluation of IMF advice on international reserves.

August 2011, Kinshasa, Democratic Republic of the Congo Presentation of the Financial and Economic Crisis and Research evaluations at the high-level seminar of the annual Africa Caucus (African Governors of the IMF and World Bank).

December 2011, Washington, D.C., USA

IEO Conference on "Ten Years of Independent Evaluation at the IMF: What Does It Add Up To?" Participants included the IMF Managing Director and other senior Management, Executive Directors, a former IEO Director, and external stakeholders.
Presentations of the Research evaluation at: the U.S. Federal Reserve; the Center for Social and Economic Research, Poland; the European Central Bank; the Bank for International Settlements; the Norges Bank, Norway; the Bank of Finland; the Treasury and Reserve Bank of Australia; the Bank of Japan; the People's Bank of China, Ministry of Finance, and Chinese Academy of Social Sciences, Beijing; the Hong Kong Monetary Authority; the Asian Development Bank Institute, Tokyo; and at a meeting of the Economic Commission for Latin America and the Caribbean, Santiago, Chile.

Presentations of the Financial and Economic Crisis evaluation at: the Ministry of Finance, Norway; the Bank of Israel; the Central Bank of Chile; the Ministry of Finance, Argentina; and the European Investment Bank, Luxembourg. 